\title{
Conservação da agrobiodiversidade e desmatamento na Amazônia: os desafios da produção de farinha de mandioca na região de Cruzeiro do Sul, Acre
}

\author{
L Maira Bueno de Carvalho \\ Universidade Estadual de Campinas, Campinas, São Paulo, Brasil
}

DOI 10.11606/issn.2316-9133.v25i25p176-199

resumo $\mathrm{A}$ valorização econômica da farinha de mandioca em Cruzeiro do Sul, Acre, está ligada à conversão da economia local, antes baseada no extrativismo da borracha, em uma fundada na agricultura, com foco no plantio de mandioca. O fabrico da farinha, por sua vez, depende de um trabalhoso processo ligado à produção familiar e garante a segurança alimentar local, enquanto a comercialização da farinha é definida por aspectos políticos e econômicos. O aumento na produção de farinha de mandioca, porém, tem sido associado à ampliação do desmatamento da região. Ao mesmo tempo, existe a ideia de proteger a farinha com o mecanismo de indicação geográfica, o que coloca em debate a necessidade de se promover a conservação da agrobiodiversidade e dos processos que a geram. O presente artigo pretende demonstrar que a valorização da farinha de mandioca de Cruzeiro do Sul impõe vários desafios ligados à sua produção

palavras-chave Mandioca; Cruzeiro do Sul (Acre); Indicação geográfica; Agrobiodiversidade; Conservação.

Agrobiodiversity conservation and deflorestation in Amazon: the challenges of the manioc powder production in Cruzeiro do Sul, Acre

abstract The economic valuation of cassava flour in Cruzeiro do Sul, Acre, is linked to the conversion of the local economy, formerly based on rubber extraction, into one based on agriculture, with a focus on cassava planting. The production of flour depends on a labor-intensive process linked to family production and ensures local food security, while the marketing of flour is defined by political and economic aspects. The increase in cassava flour production, however, has been associated with the expansion of deforestation in the region. At the same time, there is the idea of protecting the flour with the geographical 
indication mechanism, which raises the question of the need to promote the conservation of agrobiodiversity and the processes that generate it. The present article intends to demonstrate that the valorization of cassava flour of Cruzeiro do Sul imposes several challenges related to its production.

keywords Cassava; Cruzeiro do Sul (Acre/Brazil); Geographical indication; Agrobiodiversity; Conservation.

A farinha de mandioca de Cruzeiro do Sul é produzida em toda a microrregião, também conhecida localmente como Vale do Juruá, no noroeste do estado do Acre, Amazônia, uma importante zona de biodiversidade. Originalmente habitada por povos indígenas, a região manteve-se conservada ao longo do século XX, durante a economia da borracha. Depois, no Regime Militar, a região sofreu uma ampla especulação imobiliária que levou povos indígenas e seringueiros a se organizarem para lutar por direitos fundiários com base nos serviços ambientais que a região oferecia (ALMEIDA, 2004; ALLEGRETTI, 2008; COSTA, 2010).

Como resultado, nas décadas seguintes, mais da metade do Vale do Juruá tornou-se área natural protegida, com terras indígenas, parque nacional e reservas extrativistas. Em 2009, porém, essa região apresentou índice de 5,7\% de desmatamento, somente naquele ano. O índice de desmatamento em todo estado do Acre, até 2009, foi de $12 \%$. Segundo dados oficiais, o aumento do desmatamento no Vale do Juruá devia-se sobretudo à larga produção de mandioca para o fabrico da farinha nos municípios de Cruzeiro do Sul, Rodrigues Alves e Mâncio Lima. Mesmo assim, sua cadeia produtiva foi considerada meta prioritária a ser desenvolvida nos anos seguintes naquela região (MDA, 2011).

Este artigo tem como objetivo refletir sobre o papel da farinha de mandioca para as populações rurais locais e como aspectos econômicos e políticos se relacionam com suas práticas agrícolas nesse contexto. Para isso, faremos uma descrição etnográfica, apontando evidências e dados que permitam debater estratégias de proteção e incentivo da produção da farinha de mandioca de Cruzeiro do Sul.

A pesquisa foi realizada com pequenos agricultores de Cruzeiro do Sul nos meses de maio a setembro, em 2008 e 2010, para compor o doutoramento em Antropologia. Durante esse período, convivi com agricultores da Vila São Pedro e Comunidade Croa, localidades inseridas na fase I do "Projeto PACTA", um projeto multidisciplinar coordenado pelo antropólogo Mauro Almeida, da Universidade Estadual de Campinas (Unicamp) e pela bióloga Laure Emperaire, do Institute de Recherche pour le Développement (IRD), da França (PACTA, 2004).

Nossa pesquisa não integrou o Projeto PACTA, mas se baseou em pesquisa de campo nas localidades pesquisadas. Nosso objetivo era entender como discursos, práticas locais, projetos e políticas ligados à natureza interagiam naquelas localidades. Dessa forma, convivemos com agricultores, de um lado, e, de outro, com pesquisadores e técnicos governamentais. 


\section{A importância da mandioca para o consumo local}

A mandioca e seus derivados constituem a base da alimentação entre os pequenos agricultores de Cruzeiro do Sul, Acre. Durante todo período em que convivi com os agricultores da Vila São Pedro e da Comunidade Croa, percebi que esse é o alimento mais consumido, seja na forma de farinha, tapioca (feita com a fécula da mandioca), beléu (bolo de mandioca puba), beijú (feito com a massa da mandioca), mingau de carimã (feito com massa de mandioca puba), bolinho de macaxeira, ou simplesmente mandioca cozida. Os agricultores consomem mandioca ou seus derivados todos os dias (CARVALHO, 2013).

A alimentação dessa população, contudo, não deixa de ser diversificada. Somam-se a isso as carnes (de caça, boi, galinha caipira ou frango congelado), os peixes (salgados ou frescos), frutas, feijões, grãos, outros tubérculos, verduras, temperos e os chamados vinhos. A noção de que há "comida", em especial, está ligada às carnes e peixes: se uma refeição não tiver um desses alimentos, diz-se que não há comida. Já a farinha é considerada um acompanhamento fiel em todas as refeições e não precisa ser identificada como tal. Muitos agricultores dizem "hoje não tem comida, só arroz e feijão", sendo que há farinha servida.

Esse tipo de comentário ocorre porque se espera que sempre haja farinha nas refeições. A farinha ocupa um papel central na vida alimentar dessas famílias. Quando falta farinha na casa de um agricultor, por exemplo, ele sabe que pode recorrer aos vizinhos para assegurar esse alimento. Farinha é um item que não se nega a quem precisa.

A farinha de mandioca é consumida várias vezes ao dia entre os agricultores: pela manhã, no quebra-jejum, misturada à carne ou peixe salgado; no almoço, com feijão, arroz, ou alguma carne ou peixe; no lanche da tarde, misturada ao vinho de açaí e a frutas como mamão, banana e coco; e no jantar, acompanhando algum peixe, carne ou galinha.

A farinha é comida pura, no pirão - acrescida ao caldo de carnes e peixes, ou na forma de farofa -, misturada ao óleo quente de alguma fritura que se tenha feito. Pode-se ainda consumir a jacuba - farinha, água e sal - e o chibé - farinha, água e açúcar. É comum ver tambores de plástico contendo entre 25 e 50 quilos de farinha de mandioca estocados nas cozinhas dos agricultores. Essas populações costumam dizer que se eles não comem farinha nas refeições, não ficam satisfeitos! A farinha de mandioca, portanto, cumpre um importante papel de segurança alimentar local.

O consumo de farinha ocorre tradicionalmente entre essas populações desde que elas se estabeleceram na região. As populações rurais de Cruzeiro do Sul são formadas pelos descendentes dos trabalhadores nordestinos que migraram para a região durante os chamados anos de "boom da borracha", entre 1870 e 1912, e depois, com o programa "soldados da borracha", em 1943. E, apesar de 
o conhecimento ligado à produção da farinha de mandioca na Amazônia estar associado originalmente aos indígenas, estima-se que as populações rurais de Cruzeiro do Sul tenham desenvolvido uma maneira singular de produzir farinha (VELTHEM, 2007).

Existem inúmeras técnicas e instrumentos usados para fazer farinha em toda a Amazônia (TASTEVIN, 2008; EMPERAIRE et al, 2010). Mas os produtores de farinha de Cruzeiro do Sul não utilizam "tipitis", nem se recordam de seu uso pelas gerações anteriores, por exemplo. O tipiti é um instrumento usado tradicionalmente pelos indígenas da Amazônia para prensar a massa da mandioca. $\mathrm{O}$ contato poderia ter levado os migrantes nordestinos a incorporar esse instrumento, porém isso não ocorreu. Por outro lado, os agricultores contam que sempre utilizaram a bola (ou caititu) para ralar (ou cevar) a mandioca. Parece provável que esse instrumento tenha vindo do nordeste, onde já se fazia farinha usando a roda movida a braço humano - e que foi vista em funcionamento no rio Tejo, no Alto Juruá, ainda na década de 1980 (MAURO ALMEIDA, comunicação pessoal).

Há registros do comércio de farinha em Cruzeiro do Sul desde 1919 (ALMEIDA, 1992). Mas é somente a partir dos anos 1980 que a produção de farinha de mandioca aumenta exponencialmente e torna-se o principal produto comercial de Cruzeiro do Sul, com consequências para a organização social local e para o meio ambiente, conforme veremos a seguir.

\section{O fim do extrativismo da borracha e a valorização da farinha}

O processo de valorização econômica da farinha de mandioca está ligado ao surgimento de uma agricultura comercial durante as crises na economia da borracha. No primeiro ciclo da borracha, de 1870 a 1912, os seringueiros dedicavam-se exclusivamente ao extrativismo e os patrões abasteciam o seringal com alimentos e outras mercadorias, no sistema de aviamento. Porém, de 1912 a 1943, houve uma intensa crise e a rotina de trabalho dos seringueiros passou a incluir a prática da agricultura, proibida pelos patrões até então (ALMEIDA, 1992).

A crise também deu origem a dois processos de movimento populacional em toda Amazônia: os seringueiros que tinham condições voltaram para seus locais de origem ou foram para as proximidades das cidades, onde se ocuparam da extração de madeiras e agricultura para o abastecimento do mercado local (ALMEIDA; CARNEIRO DA CUNHA, 2002).

Segundo Almeida (1992), nos primeiros anos de crise da economia da borracha houve um aumento de produtos agrícolas e pecuários na lista de exportação municipal no Vale do Juruá. Entre 1917 e 1922, a região passou a exportar feijão, couros, farinha de mandioca, algodão, arroz, milho, açúcar, café, carne-seca, tabaco, tijolo, óleo vegetal, madeira e aguardente de cana. Em 1922, 53 toneladas de farinha de mandioca foram produzidas nessa região. Em 1950, Cruzeiro do 
Sul já despontava como importante centro de produção agrícola, uma exceção ao panorama econômico do Acre.

Os produtores de mandioca de Cruzeiro do Sul lembram que a farinha começou a ser considerada um produto economicamente relevante para a região entre o final dos anos 1970 e início dos anos 1980. Oséas Ferreira da Silva, eleito primeiro presidente do Sindicato dos Trabalhadores Rurais de Cruzeiro do Sul, em 1976, traz um relato interessante sobre essa relação entre a decadência do extrativismo da borracha e a comercialização da farinha de mandioca:

A primeira luta do sindicato, que foi fundado em 1976, foi unir a classe dos trabalhadores rurais, que era desunida, e implantar a lei 4.504 , dos $10 \%$ de renda. Antes os patrões obrigavam os seringueiros a vender mercadoria só para eles. Eles cobravam 60, 100 quilos de borracha como renda. Nós também brigamos com o prefeito, porque ele não deixava sair farinha de Cruzeiro do Sul. Ele achava que ia faltar na cidade. E o sindicato, vendo que o preço da borracha entrava em decadência, começou a pressionar a prefeitura para liberar o comércio da farinha para Manaus. Nós sabíamos que Manaus poderia ser um grande centro consumidor do produto. Já tínhamos estado na cidade e fomos informados da preferência pela nossa farinha. Mas a fiscalização era rigorosa nos portos da cidade para evitar que a farinha fosse escoada. $O$ sindicato então resolveu convocar todos os produtores para levarem sua farinha para o mercado do agricultor e mostrar ao prefeito que parte da produção poderia ser escoada sem que a população local fosse prejudicada. Um comerciante que estava presente no evento, seu Abraão Cândido da Silva, concordou em fazer o comércio para Manaus. E assim iniciamos a comercialização da farinha em grande escala. (Entrevista com Oséas Ferreira da Silva, 03/jul./2008)

O declínio da economia da borracha, o fim dos subsídios governamentais usados na exploração da seringa e a comercialização em grande escala da farinha de mandioca causaram diversos impactos na paisagem local. Emperaire et al (2012), utilizando imagens de satélite LANDSAT TM, ilustrou que a evolução dos espaços cultivados nos anos 1986, 1997 e 2007, nos municípios de Cruzeiro do Sul, Rodrigues Alves e Mâncio Lima, implicaram no avanço do desmatamento, em uma relação direta com o aumento da produção de farinha de mandioca nessa região. 
Diversos estudos têm vinculado o aumento do desmatamento na Amazônia com o aumento na produção agropecuária desde que a região se tornou alvo de programas governamentais de desenvolvimento, nos anos 1960 e 1970 . Nesse período começaram a ser criados os projetos de colonização (HOMMA et al, 2008; FEARNSIDE, 1997). A região de Cruzeiro do Sul, no entanto, não sofreu os impactos desses programas, pela conexão econômica que estabelecia com Manaus e não com a capital Rio Branco, onde esse processo de fato ocorreu (GOMES et al, 2012).

Durante a pesquisa etnográfica também identificamos que muitas localidades produtoras de farinha de mandioca no entorno de Cruzeiro do Sul formaram-se na primeira metade do século XX: Canela Fina, Alto Pentecoste, Cruzeiro do Vale, Vila São Pedro, Buritirana, Ramal do Alexandre, Mariana I, Mariana II e Assis Brasil. Essas localidades foram resultado de um fluxo migratório ocasionado no próprio Vale do Juruá durante as crises na economia da borracha. O único projeto de colonização que foi implementado em Cruzeiro do Sul nos anos 1970 foi o Projeto Santa Luzia, habitado por antigos seringueiros que já haviam migrado para a Amazônia nos dois primeiros ciclos da borracha, segundo relatos dos técnicos do escritório local do Instituto Nacional de Colonização e Reforma Agrária (Incra) e dos próprios moradores do Projeto Santa Luzia (CARVALHO, 2013).

Assim, apesar de o aumento do desmatamento na região de Cruzeiro do Sul estar associado ao crescimento da produção agropecuária local, isso não ocorreu devido aos projetos de colonização e das políticas desenvolvimentistas dos militares, mas à ausência de um projeto que evitasse a conversão da economia local - que era baseada no extrativismo - em uma economia baseada na agricultura.

A abertura de rodovias e estradas de terras secundárias (ramais) na microrregião de Cruzeiro do Sul a partir de meados dos anos 1970, no entanto, foi fundamental para desenvolver a cadeia produtiva de farinha de mandioca no decorrer dos anos. As transformações que ocorreram no comércio da farinha, no final do século XX, estão diretamente ligadas à criação dessas vias (CARVALHO, 2013).

Até então, na Vila São Pedro, por exemplo, os produtos agrícolas costumavam ser transportados em canoas pelo igarapé da localidade. A Vila São Pedro está localizada no quilômetro 35 da Rodovia BR-364. O território é habitado desde os anos 1930 por famílias de seringueiros vindos do Alto e Baixo rio Juruá em busca de novas áreas para a prática da agricultura. Em 1980, foi feita a regularização fundiária do território, e seus habitantes puderam adquirir lotes de até cem hectares. Em 2010, 397 famílias habitavam a Vila São Pedro, formadas em sua maioria por produtores de farinha (CARVALHO, 2013).

Segundo relatos dos agricultores da Vila São Pedro, entre o final dos anos 1930 até meados dos anos 1980, o comércio da farinha era feito em sacas de açúcar contendo a quantidade de um "paneiro" (equivalente a duas latas de que- 
rosene, medida usada nos seringais com um peso aproximado de 25 quilos). As sacas eram carregadas nas costas pelos agricultores até o porto mais próximo, no Igarapé São Francisco, e escoadas em canoas pequenas até a cidade de Cruzeiro do Sul. A viagem de canoa durava cerca de seis horas no verão e quatro horas no inverno. Na cidade, os agricultores costumavam vender sua produção para os mesmos comerciantes durante vários anos, em uma relação semelhante à do patrão-seringueiro no sistema de aviamento.

Nos anos 1980, a farinha comercializada pelos produtores da Vila São Pedro passou a ser embalada em sacas de plástico de cinquenta quilos e a ser transportada pelas vias terrestres. O papel do atravessador - chamado de "marreteiro" - começou a ter cada vez mais importância nesse comércio. Durante a pesquisa de campo, no final dos anos 2000, observamos que a prática de vender para o mesmo comerciante continuava existindo. Mas muitos vendiam para o marreteiro que pagasse melhor. Também encontramos marreteiros que migraram estrategicamente para Cruzeiro do Sul para fazer a comercialização da farinha. Os marreteiros possuíam carros "utilitários”, do tipo Pampa ou Saveiro, e iam buscar a produção nas casas dos agricultores.

Os produtores também tinham a possibilidade de embarcar a mercadoria nos caminhões oferecidos pela prefeitura de Cruzeiro do Sul, que fazia o transporte nos ramais em um único dia da semana. Um valor era cobrado por saca de farinha e outro por pessoa. Chegando à cidade, os agricultores negociavam com os marreteiros que invadiam os caminhões atrás do melhor negócio ou com os marreteiros que ficavam no mercado da farinha. Segundo os agricultores, o transporte oferecido pela prefeitura, no entanto, não é constante. Os caminhões circulam principalmente nos meses de verão, quando as estradas de terra estão em melhores condições de transporte. ${ }^{1}$

Os marreteiros vendem a farinha aos grandes comerciantes de Cruzeiro do Sul. São esses comerciantes que irão exportar o produto para o resto da Amazônia ocidental. Nos meses de chuva, durante o chamado inverno amazônico, que começa entre final de outubro e início de novembro e se estende até abril-maio, a farinha é transportada em embarcações que descem o rio Juruá até chegar ao rio Solimões, em Manaus. Na viagem de volta, as balsas vêm carregadas de mercadorias de toda espécie: estivas em geral, eletroeletrônicos, material de construção, móveis, roupas etc. No início do verão, entre junho e julho, quando as chuvas cessam definitivamente, as balsas encalham e só voltam a operar no inverno.

Nesse período, a farinha é transportada em caminhões pela estrada BR-364 até Rio Branco. Os comerciantes de Cruzeiro do Sul levam a farinha e trazem frutas, verduras e legumes oriundos do sul e sudeste do Brasil, como maçãs,

\footnotetext{
${ }^{1} \mathrm{O}$ valor pago pela saca de cinquenta quilos de farinha varia de acordo com o local onde ela é vendida. Na cidade, esse valor aumenta em torno de $15 \%$ em comparação com o valor pago pelos marreteiros nas próprias localidades.
} 
uvas, batatas, cenouras e cebolas, entre outros produtos. Pequenos comerciantes locais também levam farinha para Rio Branco e retornam com mercadorias para seus comércios. Esses comerciantes muitas vezes trocam farinha por mercadorias e são chamados de "patrões" pelos produtores que mantêm esse tipo de relação comercial.

No final dos anos 1990, o comércio da farinha de mandioca mostrou-se tão rentável que foi considerado a principal alternativa econômica ao extrativismo da borracha no Vale do Juruá. A produção da borracha passou a ser questionada pelos próprios seringueiros "porque não dava para cobrir as despesas da receita baixa; o preço da borracha natural não tinha nem como competir; e o mercado já estava praticamente liquidado da borracha no Vale do Juruá”, como explicaram importantes atores locais sobre o motivo da produção da farinha de mandioca tornar-se a pauta central do movimento rural local (Entrevistas com Antônio de Paula, em 17/08/2008; José Epaminondas Lima, em 14/07/2008; Waldemir Neto, em 04/08/2010).

A produção de mandioca, que já estava consolidada nas comunidades agrícolas do entorno de Cruzeiro do Sul desde os anos 1980, tornou-se então alvo de uma ampla estratégia de base coletiva que depois foi incluída como meta prioritária nas políticas públicas locais para o desenvolvimento da chamada "indústria da farinha”. A valorização da farinha de mandioca, portanto, foi promovida a partir de uma articulação local, em uma manifestação clara para garantir uma atividade econômica para aquelas populações. Não se trata assim de discutir as concepções locais dos produtores sobre a mandioca - valorativa e depreciativa descritas em Velthem e Katz (2012), mas da valorização econômica do produto e como isso tem repercutido localmente nesse contexto de floresta biodiversa.

\section{A floresta, os roçados e os novos arranjos do mercado}

No início do século XXI, a produção de mandioca tem sido praticada de tal forma pelos agricultores que vivem na microrregião de Cruzeiro do Sul que esta passou a ser considerada localmente como uma "monocultura de mandioca" - ainda que a mandioca seja produzida por meio de uma economia familiar e em lotes separados. Em 2010, o governo local estimava que pelo menos $10 \mathrm{mil}$ famílias estavam envolvidas com a produção da farinha de mandioca em todo Vale do Juruá. ${ }^{2}$

\footnotetext{
${ }^{2}$ Dados apresentados pela Secretaria de Extensão Agroflorestal e Produção Familiar (Seaprof). Em 04/jun./2008, Cruzeiro do Sul (Acre). O Censo Agropecuário de 2006 do IBGE indica que foram produzidos em todo estado do Acre 180.265 toneladas de mandioca em 10.982 estabelecimentos; e 21.120 toneladas de farinha de mandioca em 6.337 estabelecimentos, sendo que 14.960 toneladas foram vendidas (IBGE, 2006, p. 741; p. 750). Não existem dados específicos sobre a produção de farinha de mandioca na região de Cruzeiro do Sul nesse Censo Agropecuário (IBGE, 2006).
} 
Dados oficiais sobre a produção agrícola municipal indicam que foram produzidos 133.276 toneladas de mandioca em Cruzeiro do Sul em 2013. Somando a produção de todo Vale do Juruá, que inclui os municípios de Cruzeiro do Sul, Mâncio Lima, Marechal Thaumaturgo, Porto Valter e Rodrigues Alves, no mesmo ano foram produzidos 316.309 toneladas de mandioca (IBGE, 2013).

A atuação da Cooperativa das Associações dos Seringueiros e Agricultores do Vale do Juruá (Casavaj) teve um papel central no processo da valorização econômica da farinha. A Casavaj foi instituída em março de 1997, com a participação de treze associações de produtores rurais, das quais destaco as associações das localidades Canela Fina, Alto Pentecoste, Cruzeiro do Vale, Valparaíso, Lagoinha, Belo Monte, Projeto Santa Luzia, Vila São Pedro, Liberdade e Reserva Extrativista Alto Juruá (Reaj).

Segundo relatos de líderes comunitários e da própria diretoria da cooperativa, o foco inicial da Casavaj era alavancar a produção da borracha, mas, devido à crise nesse mercado, a cooperativa passou a trabalhar com farinha de mandioca. O novo objetivo da cooperativa era elevar o preço da farinha, melhorar as condições sanitárias de produção e investir no marketing do produto.

Contam os produtores de farinha que quando a Casavaj começou a negociar a produção, no início dos anos 2000, a saca de cinquenta quilos de farinha era vendida aos marreteiros por $R \$ 12,00$. Em 2005, a saca chegou a $R \$ 47,00$. Em 2008, quando estive pela primeira vez em Cruzeiro do Sul, a saca estava custando $\mathrm{R} \$ 35,00$. Dois anos depois, em 2010, a saca de cinquenta quilos de farinha era comercializada em Cruzeiro do Sul por $\mathrm{R} \$ 80,00$.

Em dez anos, portanto, a saca de cinquenta quilos de farinha de mandioca passou de R \$ 12,00 para R \$ 80,00. Segundo relatos, a atuação da Casavaj regulou o mercado. A Casavaj desarticulou os atravessadores e, com isso, elevou o preço do produto. Ao mesmo tempo, o governo estadual incentivou a produção de farinha. Nos três mandatos em que a coligação "Frente Popular" esteve à frente do governo estadual (1999 a 2010), 50 casas de farinha foram reformadas e mais 150 "casas de farinha moderna" foram implementadas em Cruzeiro do Sul. A prefeitura do município também construiu inúmeras outras casas de farinha, e os próprios agricultores contribuíram com a construção de novas casas (Entrevista Waldemir Neto, coordenador da Seaprof, em 10/jun./2010).

Como resultado, houve um aumento significativo na exportação de farinha de mandioca em Cruzeiro do Sul entre 2000 e 2009. Os dados levantados pela Secretaria de Estado da Fazenda e Gestão da Agência de Cruzeiro do Sul (Sefaz, 2010), a partir da emissão de notas fiscais referentes à saída de farinha de mandioca do município, indicam que a exportação passou de 5.915 toneladas anuais de farinha de mandioca em 2000 para 13.115 toneladas em 2009 (Tabela 1). 
Vendas em sacas de $50 \mathrm{KG}$

\begin{tabular}{|c|c|c|c|c|c|c|}
\hline \multirow[b]{2}{*}{ Ano } & \multicolumn{3}{|c|}{ Vendas em sacas de 50KG } & \multicolumn{3}{|c|}{ Vendas em toneladas } \\
\hline & Acre & $\begin{array}{l}\text { Outros } \\
\text { Estados* }\end{array}$ & Total & Acre & $\begin{array}{l}\text { Outros } \\
\text { Estados* }\end{array}$ & Total \\
\hline 2000 & 17.922 & 100.386 & 118.308 & 890 & 5.025 & 5.915 \\
\hline 2001 & 18.041 & 85.789 & 103.830 & 900 & 4.291 & 5.191 \\
\hline 2002 & 16.468 & 62.312 & 78.780 & 820 & 3.119 & 3.939 \\
\hline 2003 & 35.630 & 144.125 & 179.755 & 1.780 & 7.207 & 8.987 \\
\hline 2004 & 66.727 & 168.558 & 235.285 & 3.336 & 8.428 & 11.764 \\
\hline 2005 & 40.932 & 161.084 & 202.016 & 2.046 & 8.054 & 10.100 \\
\hline 2006 & 33.007 & 145.446 & 178.453 & 1.650 & 7.272 & 8.922 \\
\hline 2007 & 34.345 & 220.809 & 255.154 & 1.717 & 11.040 & 12.757 \\
\hline 2008 & 20.731 & 186.717 & 207.448 & 1.036 & 9.336 & 10.372 \\
\hline 2009 & 13.148 & 249.160 & 262.308 & 657 & 12.458 & 13.115 \\
\hline
\end{tabular}

* Outros Estados: Amazonas, Pará, Rondônia e Mato Grosso. Fonte: dados da SEFAZ - Cruzeiro do Sul, 2010.

Em 2004, porém, a Casavaj firmou um convênio com o governo federal que desarticulou a cooperativa, mas não interrompeu o desenvolvimento dessa economia. Ao contrário, os dados da tabela mostram que, a partir daquele ano, a produção de farinha de mandioca aumentou.

Contam os dirigentes da Casavaj que a Companhia Nacional de Abastecimento (Conab), empresa pública vinculada ao Ministério da Agricultura, repassou uma verba de cerca de 2 milhões de reais para financiar a produção de farinha de mandioca. Com essa verba, a Casavaj realizou a chamada "compra antecipada": cerca de 900 cooperados receberam um valor entre $\mathrm{R} \$ 1.000,00 \mathrm{e}$ R\$ 2.500,00 para começar a produção da farinha. Ao final da safra, o produtor deveria devolver esse valor para a Casavaj na forma de farinha.

Muitos cooperados que receberam o valor antecipado, no entanto, não abasteceram a cooperativa com farinha. Dentre as razões apontadas pelos agricultores por não terem entregue sua produção estavam "o surto de malária que atrapalhou o trabalho; a lagarta mandarová que atacou os roçados de mandioca; e a falta da assistência técnica prevista, que não cumpriu o contrato”. A Casavaj 
ficou sem a produção esperada, tornou-se inadimplente junto à Conab e não conseguiu participar de novas licitações ou outras ações governamentais. A Casavaj também perdeu o capital de giro - fundamental para continuar comprando a produção - e se desarticulou completamente.

A opção pela compra antecipada foi proposta pelo governo estadual, que mediou a participação da Casavaj na licitação da Conab. A proposta da Casavaj era adotar a "compra direta". Muitos produtores rurais de Cruzeiro do Sul já haviam contraído algum tipo de financiamento, através de programas de crédito como FNO e Pronaf. Sabia-se que a maioria não havia quitado suas dívidas e que a opção pela compra antecipada poderia ser equivocada. O governo, porém, defendia que o adiantamento de capital iria fortalecer os produtores (entrevista com a diretoria da Casavaj, 14/jul./2008; entrevista com a diretoria da Seaprof, 04/ago./2010).

A compra antecipada fez com que a Casavaj fracassasse financeiramente, principalmente perdendo seu valor simbólico, como orgulho, autoconfiança e outros benefícios não monetários de que fala Hirschman (1987, p. 42) e que "pode até mesmo ser considerado como início de liberação, especialmente de grupos que há muito sofrem e são oprimidos”. Segundo o autor, os benefícios simbólicos intensificam os benefícios monetários de uma cooperativa. Se a cooperativa estiver em dificuldades financeiras, os benefícios simbólicos se transformarão em perdas à medida que o orgulho for ferido, a autoconfiança for abalada e mais uma vez se dissiparem as esperanças de liberação.

Com a desestruturação da Casavaj, as ações coletivas ligadas à produção e comercialização da farinha de mandioca se dissiparam. Ainda assim, a indústria da farinha foi mantida como política estadual de desenvolvimento na microrregião de Cruzeiro do Sul. Ao privilegiarem a farinha de mandioca como estratégia de desenvolvimento, as políticas locais colocaram em evidência como a floresta tem sido articulada.

As organizações de base estão enfraquecidas e as instâncias governamentais têm apostado em uma noção agrícola produtivista sem oferecer medidas que recuperem o uso do solo para evitar novos desmatamentos ou mesmo que preservem a diversidade biológica e cultural ligada à produção tradicional da farinha, como veremos a seguir.

\section{A indicação geográfica como política de valorização cultural e seus limites para a conservação da agrobiodiversidade}

Estima-se que a produção de farinha de mandioca tenha movimentado 80\% da economia de Cruzeiro do Sul nos anos $2000 .^{3}$ A importância econômica que

\footnotetext{
${ }^{3}$ Nelson Liano Jr. Projeto vai melhorar farinha de Cruzeiro do Sul. Jornal Página 20. Rio Branco, 10/jul./2003. Disponível em: <http://www2.uol.com.br/pagina20/7julho2003/site/10072003/c_031007.htm>. Acesso em: 19/jun./ 2009.
} 
a farinha de mandioca adquiriu no município iniciou um debate sobre a proteção da farinha. Agricultores, organizações do terceiro setor, instâncias governamentais e pesquisadores vêm discutindo intensamente essa questão. Existe uma preocupação em se evitar que aconteça um processo semelhante ao da biopirataria da borracha, maneira como as populações locais referem-se ao contrabando da espécie Hevea brasiliensis por botânicos ingleses e que viabilizou seu plantio em larga escala nas colônias inglesas, iniciando assim o esgotamento do ciclo da borracha em toda Amazônia.

A farinha de Cruzeiro do Sul remete à ideia de uma farinha benfeita e saborosa em toda Amazônia Ocidental. Da mesma forma, as populações utilizam a expressão biopirataria da farinha para referirem-se à farinha de mandioca produzida fora da região de Cruzeiro do Sul, mediante outras técnicas, mas que utilizam o nome da cidade para identificar o produto. Pensando nisso, a Casavaj, em conjunto com a Comissão Pastoral da Terra (CPT) e o Sindicato dos Trabalhadores Rurais (STR), sugeriu inicialmente o uso de um "selo verde" para proteger a farinha.

Segundo essas instituições, a farinha de Cruzeiro do Sul comercializada em Manaus é misturada com outras farinhas e vendida em embalagens identificadas como originárias de Cruzeiro do Sul para ter melhor inserção no mercado. Relatos de agricultores também indicam que comerciantes de farinha produzida em outras cidades acreanas, como Sena Madureira e Rio Branco, utilizam o nome de origem de Cruzeiro do Sul. O selo verde pretendia garantir a origem e a qualidade da farinha. A menção ao "verde" foi pensada como uma maneira de remeter o consumo do produto à noção de "defesa da floresta".

Posteriormente, o Ministério da Agricultura, na esteira da política de registrar produtos culturais ligados à produção agrícola, sugeriu a indicação geográfica como instrumento de proteção da farinha. A indicação geográfica é um dos mecanismos de propriedade intelectual, ao lado de patentes, desenhos industriais e marcas, que são regulados no Brasil pela lei no 9.279, de 14 de maio de 1966.

A lei não define o que é indicação geográfica, mas estabelece suas espécies: constitui indicação geográfica: 1) a indicação de procedência ou 2) a denominação de origem. A indicação de procedência pode ser o nome geográfico de país, cidade, região ou localidade de seu território, que se tenha tornado conhecido como centro de extração, produção ou fabricação de determinado produto ou de prestação de determinado serviço. Já a denominação de origem pode ser o nome geográfico de país, cidade, região ou localidade de seu território, que designe produto ou serviço cujas qualidades ou características se devam exclusiva ou essencialmente ao meio geográfico, incluídos fatores naturais e humanos (art. 177 da lei no 9.279/96).

O Ministério da Agricultura vem incentivando a indicação geográfica a produtos ou serviços característicos do seu local de origem, o que lhes atribui repu- 
tação, valor intrínseco e identidade própria. São produtos que apresentam uma qualidade única em função de princípios naturais, como solo, vegetação, clima e o saber fazer. Entre os produtos que já foram registrados estão os vinhos do Vale dos Vinhedos, no Rio Grande do Sul; o café produzido na região do Cerrado Mineiro; e a cachaça de Paraty. Existe uma centena de produtos considerados potenciais para serem registrados sob a indicação geográfica no Brasil. No Acre, a expectativa é de registrar a farinha de mandioca, o abacaxi, o urucum, a castanha do Brasil e essências florestais (MINISTÉRIO DA AGRICULTURA, 2016).

No campo científico, por sua vez, os pesquisadores vêm discutindo a proteção da farinha de Cruzeiro do Sul no âmbito da conservação da agrobiodiversidade e dos processos que a geram. Duas questões, em especial, norteiam a discussão: assegurar os direitos intelectuais e a remuneração dos produtores ou detentores do patrimônio cultural, e assegurar a perpetuação de formas culturais de produzir (CARNEIRO DA CUNHA, 2005).

Espera-se que as indicações geográficas, além de protegerem comercialmente a farinha, sejam capazes de proteger os conhecimentos ligados à sua produção. O debate tem a ver com a proteção da diversidade da mandioca. Segundo Emperaire (2002), o manejo individualizado da mandioca, os novos hábitos alimentares, a larga comercialização da farinha de mandioca, as transformações nos sistemas de produção e a introdução de novas variedades pelas instituições de extensão rural, ao privilegiarem certas variedades, contribuem para a erosão genética.

Nesse sentido, os pesquisadores entendem que a indicação geográfica pode ser uma boa alternativa para proteger a farinha de mandioca, mas insuficiente para conter a erosão dos conhecimentos ligados a ela. Para Emperaire (2005), as indicações geográficas são capazes de se opor à agricultura modernizada, criar uma relação entre consumidores e populações locais ou mesmo um estatuto de reivindicação por um grupo social, mas não contemplariam os antagonismos entre sistemas de conhecimentos locais e normas legais, por exemplo.

Emperaire (2012) defende que as indicações geográficas no Brasil levem em conta "um contexto social e territorial em construção". A existência da indicação geográfica no caso da farinha de Cruzeiro do Sul responde à preocupação dos agricultores em reconhecer seus conhecimentos e valorizar o produto economicamente. Para o governo, a indicação geográfica revela a consolidação econômica de arranjos produtivos locais ligados à identidade regional. Porém, somente as normas sanitárias e visuais têm sido privilegiadas, sem levar em conta o modelo particular de posse da terra e a sustentabilidade. Por essas razões, o produto protegido pela indicação geográfica deveria ser melhor discutido no que se refere ao território onde é produzido, aponta a autora.

O mecanismo de indicação geográfica não deveria ser visto, portanto, como uma estratégia econômica ou uma forma de incentivar a produção local, mas 
como uma possibilidade de assegurar o manejo da diversidade da mandioca e o modo de preparo da farinha pelas populações locais. Se o que está em jogo é o processo de produção e não o produto final, a alternativa para proteger a farinha de mandioca poderia então vir de uma utilização mais eficiente do produto cultural que essas populações têm a oferecer. Para isso, parece fundamental entender a conservação in-situ da mandioca e sua conexão com o fabrico da farinha. Veremos abaixo como a mandioca é manejada e a importância das relações sociais dentro do território para a sua conservação.

\section{O manejo local da mandioca e as trocas de maniva}

Para explicar o manejo local da mandioca, vamos descrever as práticas agrícolas observadas em dois territórios distintos: a Vila São Pedro, mencionada anteriormente, e a Comunidade Croa, distante trinta quilômetros daquela e inserida em uma área de preservação ambiental.

Vimos que na Vila São Pedro a farinha de mandioca constitui o principal produto agrícola que mantém a economia local. Já na Comunidade Croa, embora a maioria dos moradores produza farinha, o comércio da produção é pequeno. Em 2010, a Comunidade Croa era habitada por 28 famílias remanescentes de seringueiros, dispersas ao longo do rio Croa. O território está inserido em uma floresta de várzea e sujeito a inundação sazonal. Lá, a produção de farinha local é voltada principalmente para o consumo interno (CARVALHO, 2013).

Apesar de o papel da mandioca ser diferente nessas duas localidades, seu processo de plantio e o de produção da farinha são semelhantes: os roçados de mandioca estão quase sempre beirando a mata. Os agricultores utilizam tradicionalmente o sistema de corte-e-queima e descanso da terra, avançando sobre a floresta primária à procura de novos solos para o plantio. Insumos agrícolas, como adubo e fertilizante, não são usados nesses roçados.

O plantio da mandioca é feito apenas com enxadas, baldes ou cestos e a força corporal. Primeiro, o agricultor, utilizando uma enxada, abre pequenas covas no solo com cerca de cinco centímetros de profundidade. As covas ficam distantes, em média, um metro umas das outras. À primeira vista, a forma como as covas são abertas parece um tanto aleatória. Não existe uma ordem rígida, como numa plantação, em fileiras. No entanto, existe um padrão para abrir as covas. Elas não podem se distanciar muito umas das outras. E devem ocupar todo o espaço da área limpa.

As covas são então preenchidas com pedaços de maniva, o caule da planta da mandioca (estacas), e cobertas com terra empurrada pelos próprios pés dos agricultores. Em geral, os agricultores guardam as manivas de plantios anteriores no próprio terreno. No momento do novo plantio, as manivas são cortadas em pedaços de cerca de sete centímetros e alocadas dentro de cestos de palha ou baldes de plástico para serem distribuídas entre as covas abertas.

Depois de oito meses, às vezes até antes, a partir do sexto mês, tem início a 
colheita, que pode se estender até o décimo segundo mês. Durante esse período, os agricultores costumam fazer "três limpas": eles precisam capinar o roçado, arrancando mato e outras plantas ao redor dos pés de mandioca, para que ela possa crescer e se desenvolver.

A "roça", como os agricultores chamam a mandioca, pode ser de várias "qualidades". Emperaire (2002, p. 191) descreve a "qualidade" como

Um conjunto de indivíduos que apresenta características suficientemente semelhantes - e suficientemente diferentes daquelas observadas em outros conjuntos - para ser reconhecida como um grupo à parte e identificada por um nome que lhe é próprio.

A nomeação da qualidade dá sentido ao objeto e permite sua inserção em um universo de referências culturais. A noção de qualidade, no entanto, "pode encobrir diversos níveis de homogeneidade biológica”, diz Emperaire (2002, p. 191). Existe ainda a noção de que a mandioca pode ser "amargosa" ou "brava", considerada tóxica pela população local, em contraposição com a mandioca "mansa", também chamada de "macaxeira". A diferenciação dos termos para saber se a mandioca é brava ou mansa, no entanto, não é rigorosamente utilizada pela população, principalmente pelos mais jovens: para eles, mandioca e macaxeira são sinônimos.

No "Ramal dos Paulino", Vila São Pedro, encontramos dez qualidades de "roça" em 2010: uma qualidade de mandioca mansa, denominada "amarelinha" ou "rasgadinha"; e as mandiocas bravas "mansa-e-braba", "milagrosa", "branquinha”, "curimem-roxa”, "curimem-preta”, "curimem-branca”, "caboquinha”, "chico-anjo" e "rasgadinha-preta". No Croa encontramos sete qualidades de roça, cinco das quais também foram encontradas no Ramal dos Paulino: "amarelinha" ou "rasgadinha", "curimem-roxa”, "caboquinha”, "branquinha” e "chico-anjo". E as qualidades "santa-maria" e a "maria-faz-ruma", que amadurece em seis meses. A qualidade "amarelinha" não é usada para fazer farinha, considerada excelente para ser consumida cozida.

As diversas qualidades de mandioca que circulam nas localidades são resultado das relações sociais que os moradores estabelecem dentro e fora da localidade. A diversidade agrícola produzida nessas localidades se dá através de trocas entre parentes, vizinhos e amigos. Conta um agricultor da Vila São Pedro, por exemplo, que as qualidades "curimem-roxa", "chico anjo" e "caboquinha" foram trazidas por ele de uma partida de futebol ocorrida há anos na localidade vizinha Colônia Pentecoste. Depois que ele colheu as batatas da primeira plantação, começou a trocar novas manivas com seus vizinhos e assim espalhou a qualidade pelo ramal.

Nem sempre o agricultor revela todas as qualidades que ele planta. Em geral, o agricultor diz que possui certas qualidades, "mas é pouca coisa", e não se lembra na hora de identificar todas as qualidades do roçado. Suponho, no entanto, que 
isso também tem a ver com uma certa discrição quanto ao seu acervo pessoal de manivas. A disponibilidade de manivas é fundamental para plantar mandioca. Um agricultor prevenido fará o plantio em um curto período de tempo logo após ter arrancado as manivas maduras do solo. Quando isso não é possível, ele terá de recorrer aos parentes, amigos e vizinhos para poder fazer sua plantação.

Muitas vezes os agricultores acabam plantando diversas qualidades de mandioca em um único roçado. A doação ou troca de manivas contribui com essa diversidade. Sobretudo, a incorporação de diferentes manivas no mesmo roçado é estratégica para atender às expectativas do agricultor: ele pode querer guardar uma qualidade de roça que fique madura em maior ou menor tempo; que resulte em uma farinha "pesada" (mediante o uso de raízes que possuem menos água); ou então uma qualidade que garanta a alimentação imediata - qualidades "mansas” que são consumidas cozidas, ou seja, que não precisam passar pelo processo de transformação em farinha.

Pode-se ainda querer novas qualidades para incorporar ao acervo pessoal de manivas variadas ou uma qualidade específica que se adapte melhor ao solo do agricultor. O plantio de qualidades diferentes no mesmo roçado também assegura uma boa colheita e melhora o sabor da farinha. O agricultor diria que é sempre prudente plantar mais de uma qualidade no mesmo roçado.

\section{As casas de farinha}

Depois de colhidas, as mandiocas são levadas para as "casas de farinha", onde serão processadas. $\mathrm{O}$ fabrico da farinha é um processo trabalhoso, que agrega todos os familiares e, por vezes, diaristas. Durante a pesquisa etnográfica, participei de inúmeros processos de fabricação de farinha, com diversas famílias e em casas de farinha com tecnologias variadas. Em todos esses processos, a forma como a farinha era produzida era semelhante. As diferenças recaíam sobre as relações em torno da casa de farinha e sua representação enquanto um espaço de produção (CARVALHO, 2013).

As casas de farinha são compartilhadas por várias famílias, ligadas por parentesco ou não. Cada casa de farinha possui um dono, ainda que outras pessoas tenham colaborado com a sua construção, ou mesmo que a casa de farinha tenha sido doada pelo governo. É considerado dono da casa de farinha o proprietário do terreno onde ela foi construída - a noção de direito sobre determinando espaço entre os agricultores é fundamental para definir o que é deles. De modo que a decisão de uma família em utilizar determinada casa de farinha é motivada por fatores como a proximidade da casa de farinha em relação ao seu roçado, a afinidade que essa família tem com o dono da casa de farinha ou ainda a disponibilidade desta.

O dono da casa de farinha não costuma cobrar de seus parentes pela sua utilização. Já as famílias que não têm parentesco com o proprietário, podem ou não ser cobrados. O valor varia e é chamado de "renda": cobra-se uma porcentagem da 
produção total, em um sistema semelhante ao utilizado no extrativismo da borracha.

Na Vila São Pedro, as casas de farinha estão localizadas ao lado das moradias dos agricultores, distante dos roçados, e a mandioca é transportada em carroças de boi. Na Comunidade Croa, em geral, as casas de farinha estão localizadas no próprio roçado. Quando isso não acontece, a raspagem da mandioca é feita no roçado, em espaços improvisados com palhas e lonas para garantir sombra durante essa etapa. A mandioca descascada é então alocada em cestos de cipó, que são carregados nas costas até a casa de farinha.

As casas de farinha diferenciam-se entre si no tocante ao tamanho e ao material usado na sua construção. Existem as casas de farinha doadas pelo governo estadual, com telhas de alumínio, paredes de madeira e telas de proteção nas paredes. As casas de farinha doadas pelo governo municipal, com telhas de alumínio e cimento para forrar o chão. E as casas de farinha "tradicionais", construídas pelos agricultores sem auxílios governamentais, com cobertura de palha e chão de barro.

Apenas as casas de farinha doadas pelo governo estadual possuem paredes; as outras, não. Os auxílios governamentais também financiam os instrumentos usados dentro desses estabelecimentos, como os parafusos da prensa e as chapas de torrar. Ali também se encontram prensas de varão (prensa de pau), produzidas pelos próprios donos.

O governo define a qualidade da farinha em "tipo 1" e "tipo 2" segundo as condições de higiene em que a farinha é produzida. As casas doadas pelo governo estadual são consideradas as que oferecem melhores condições de higiene, visto que são cobertas com telhas de alumínio, possuem piso de cimento, telas de proteção nas laterais, além de possuir uma arquitetura que preza pelo completo fechamento da casa. Estima-se que, dessa maneira, a casa será bem asseada, protegida de elementos externos que possam contaminar a farinha, principalmente da presença de animais. A farinha produzida nesses espaços é considerada "tipo 1".

Nas casas abertas, em especial as casas de farinha "tradicionais", os animais, principalmente galinhas e cachorros, entram e saem a qualquer hora. Não há nenhuma tela de proteção ou porta impedindo a sua passagem. A farinha produzida nesse tipo de construção é considerada "tipo 2". Nota-se, contudo, que a arquitetura da casa de farinha do governo estadual não evita que os animais entrem na casa, já que a porta está sempre aberta enquanto os trabalhadores estão lá dentro.

Os agricultores costumam avaliar a qualidade da farinha de outra forma. Para Silveira (2009), a percepção sobre a qualidade da farinha leva em conta a qualidade do solo em que a mandioca foi produzida, o tempo de colheita da mandioca e a atenção a todas as fases do processo de produção, desde o cuidado e dedicação do produtor, o acesso à eletricidade e à água durante a produção até o escoamento do produto.

Durante a pesquisa de campo, contudo, percebemos que tanto os agricultores como os marreteiros têm um paladar extremamente apurado para avaliar a 
qualidade de uma farinha. Eles são superexigentes e críticos com a cor, o sabor e a textura. E estão constantemente avaliando novas farinhas, seja aquela produzida pelo vizinho, a comprada no mercado ou, no caso específico dos agricultores, a farinha que eles mesmos produziram.

Os agricultores dizem que a farinha pode ser "boa" em contraponto à farinha "ruim". Mas é raro algum produtor dizer que sua farinha é ruim, a farinha "só não é boa". A farinha ainda pode ser "muito boa" ou então "de primeira", classificação usada para as melhores farinhas. O parâmetro usado para avaliar se a farinha é "de primeira" passa pelo volume produzido por dia: a produção de três a quatro sacas de cinquenta quilos de farinha por dia confere ao produto o status de farinha "de primeira"; já o volume de sete a dez sacas produzidas por dia fará com que a qualidade da farinha seja "de segunda". Ou seja, quanto menos farinha for produzida por dia, melhor será sua qualidade.

A farinha "de primeira" é reconhecida como tal devido, sobretudo, a sua granulação: a farinha não pode ser nem muito fina nem muito grossa. Deve ser granulada por igual. Não pode ter "pó" ou "fiapo" e deve ser colorida (pelo uso do açafrão da terra) por igual, não pode ter "caroço branco". Essas características indicam que todo o processo de produção foi feito com mais cuidado e, em especial, que a farinha foi bem "peneirada", "escaldada" e "torrada". Uma farinha "de primeira" costuma ser peneirada de duas a três vezes, com diferentes tipos de peneiras. A torração benfeita é fundamental. A farinha deve ficar bem seca, mas o forno de torrar não pode "ter muita pressão", ficar extremamente quente, para não queimar.

A higiene do ambiente em que a farinha é produzida também é importante para definir a qualidade dela, mas não é considerada primordial, como nos critérios do governo. Os marreteiros, por sua vez, negociam farinhas "de primeira" e "de segunda". Eles identificam se a farinha é "de primeira" ou "de segunda" pela cor, textura, sabor e pelas as condições de higiene da casa de farinha. Por fim, muitos marreteiros e agricultores referem-se à qualidade da farinha como uma "farinha de segunda boa". Ou seja, mesmo entre as farinhas "de segunda", existe uma percepção variada.

\section{A farinhada}

O processo de produzir farinha chama-se "farinhada". Ainda que uma casa de farinha tenha um dono, ela é compartilhada com várias famílias. Porém, cada família realiza sua própria farinhada, separadamente e em dias diferentes: a casa de farinha é compartilhada; mas a produção não. Considera-se o dono da farinhada o dono do roçado de mandioca que será utilizado para fazer farinha.

O dono da farinhada é responsável por gerenciar a casa de farinha. A produção da farinha é feita em família, mas, quando há necessidade, contrata-se diaris- 
tas. Todos os que participam da farinhada são recompensados, seja na forma de farinha, diárias em dinheiro ou troca de dias. ${ }^{4} \mathrm{O}$ dono da farinha também deve oferecer as refeições durante todos os dias de farinhada: quebra-jejum, almoço, lanche e, às vezes, janta.

A farinhada começa quando a mandioca é arrancada, raspada, lavada, cevada e a massa é prensada. A torração é feita no dia seguinte. Esse processo de produção da farinha é chamado de "uma puxada". O número de puxadas necessárias para produzir a farinha depende de inúmeros fatores, igualmente importantes: 1) a quantidade de farinha que se quer produzir, seja para alimentar a família durante um dado período ou para comercializar a produção; 2) a disponibilidade da casa de farinha, já que o espaço é compartilhado; 3) a quantidade necessária para pagar uma dívida ou então levantar capital para as compras do cotidiano; 4) a quantidade de mandioca madura no roçado; e, finalmente, 5) a disponibilidade de mão de obra para fazer a farinha. Há casos, portanto, em que a farinhada é feita em uma ou duas puxadas, ou então de dez a treze puxadas, até a última mandioca madura do roçado.

As atividades ligadas à produção da farinha são divididas por gênero, porém não existe uma divisão sexual rígida do trabalho durante a farinhada. Homens e mulheres podem exercer as mesmas atividades, a não ser quando o trabalho é remunerado: nesse caso, somente as mulheres "raspam", ou seja, descascam e lavam a mandioca, e os homens arrancam a mandioca no roçado, levam para a casa de farinha, "temperam" e "cevam" a mandioca, prensam a "massa", "escaldam", "peneiram" e finalmente "secam" a farinha.

O dono da farinha é responsável por sua venda. Geralmente os homens são os donos dos roçados e, portanto, os donos da farinha. Mas há mulheres viúvas que se tornam chefe da família ou ainda mulheres agricultoras casadas com não agricultores; nesses casos, a produção, a venda e o dinheiro arrecadado com o produto são responsabilidade delas.

Nem todos os produtores vendem sua farinha. Existem os agricultores que preferem trocar a farinha por outros produtos. Por exemplo, uma família de produtores trocou sua farinha, sete sacas no total, por uma mesa de sinuca (as trocas são muito praticadas, não apenas com farinha, mas com outros produtos, como boi, moto, casa etc.).

As crianças participam da farinhada ajudando os adultos ou apenas participando da agitação que envolve toda a produção. A farinhada não é apenas um processo produtivo, mas um momento de socialização. As mães levam seus filhos pequenos para a farinhada, já que estarão ocupadas durante esse período e cabe a elas cuidar das crianças. Amigos e parentes que não estão necessariamente participando da farinhada também costumam visitar a casa de farinha motivados por conversas,

${ }^{4}$ Em 2008, uma diária de torrador na Vila São Pedro variava de R\$10,00 a R\$ 12,00. Em 2010, esse valor passou para a faixa de $\mathrm{R} \$ 20,00$ a $\mathrm{R} \$ 25,00$. 
café e comida, e costumam ajudar, um pouco que seja, em alguma atividade.

Meninos a partir de oito anos de idade já são vistos ajudando a arrancar a mandioca do solo. Depois, já na casa de farinha, ajudam a descascar a mandioca, pegar a "massa" de mandioca com baldes e colocar no "forro", um tecido telado que faz com que a água da massa de mandioca escorra ("manipuera”). Aos dez anos, um menino já costuma ser remunerado de alguma maneira pelos seus serviços. Crianças menores, a partir de quatro anos e de ambos os sexos, já começam a brincar de descascar mandioca e aos poucos vão aprendendo a manusear facas afiadas no ofício da "raspagem", como é chamada essa etapa na produção da farinha.

\section{O tempo de farinhada}

O processo de farinhada é semelhante em toda microrregião de Cruzeiro do Sul, demonstrando haver um padrão. O tempo de farinhada, contabilizado através do termo "puxada", porém, varia. Quanto maior a produção de farinha, maior o número de "puxadas". Uma farinhada de duas puxadas leva em torno de quatro dias de trabalho para ser concluída, desde a limpeza da casa de farinha, a colheita da mandioca até a finalização do processo.

O maior volume de farinha é produzido durante o verão amazônico, época em que param as chuvas e as mandiocas costumam completar um ano de plantio. Durante esse período, observamos farinhadas com inúmeras puxadas: duas semanas seguidas, com pausa para descanso aos sábados e domingos. Em uma ocasião em especial, participei de uma farinhada de três semanas seguidas - até acabar o roçado.

Note que a farinha é feita em dois fornos retangulares - um para "escaldar", outro para "secar". Segundo relatos dos agricultores, o uso dos dois fornos na produção de farinha nos arredores de Cruzeiro do Sul foi iniciado no final dos anos 1970, momento em que a produção passou a ser exportada para Manaus. Até então, utilizava-se somente um forno. Mesmo assim, o processo de "escaldar" e "secar" já eram executados: depois de cerca de quinze minutos escaldando determinada quantidade de massa, retirava-se essa porção do forno para que fosse guardada dentro de uma bacia. Isso se repetia até terminar toda massa disponível. Somente após essa etapa a massa escaldada voltava para o forno, onde finalmente era "torrada".

Estudos feitos na Reserva Extrativista Alto Juruá nos anos 2000 indicam que a produção da farinha utilizava apenas um forno, mas uma família do rio Bajé já possuía dois fornos para torrar farinha, fato que foi considerado inédito naquela região (COSTA, 2010; PANTOJA et al, 2002; POSTIGO, 2010). Segundo Postigo (2010), a produção de farinha de mandioca vem se transformando na principal atividade econômica na REAJ desde que os seringueiros deixaram de cortar 
seringa. De modo que a incorporação de um forno a mais entre os agricultores da REAJ pode indicar o início de uma transformação na produção de farinha de mandioca tal como ocorreu na região de Cruzeiro do Sul no final do anos 1970.

\section{Considerações finais}

Vimos que a produção de mandioca e o fabrico de farinha em Cruzeiro do Sul dependem de um rico processo cultural que põe em movimento manivas e saberes, envolve relações sociais, garante a soberania alimentar e impulsiona a economia regional. Esse processo cultural foi formado ao longo do século XX, nessa região específica, e tem sido considerado fundamental para se conservar a diversidade local de mandiocas bem como para garantir a especificidade dessa farinha.

No entanto, a expansão da produção de farinha de mandioca de Cruzeiro do Sul está associada ao aumento nos desmatamentos dessa região. A defesa da "farinha de Cruzeiro do Sul" carrega então a um paradoxo. A importância econômica que a farinha de mandioca alcançou é comparada ao papel da seringa no passado, e a ideia de que pode haver novas crises econômicas impulsiona as políticas locais.

Mas, ao contrário da borracha, que era um produto extrativista e que mantinha a floresta em pé, a farinha é um produto agrícola que tem avançado sobre a floresta. De forma que o incentivo à sua produção ou mesmo a noção de que a farinha deve ser protegida reforçam o papel econômico que o produto em si promove, e não as potencialidades ambientais e culturais que estão envolvidas no próprio processo de produção.

O mecanismo de indicação geográfica, por exemplo, foi proposto sem que houvesse medidas para recuperar o uso do solo ou mesmo para preservar a diversidade biológica e cultural ligada à produção tradicional da farinha. Por outro lado, as organizações de base, que historicamente vinham atuando em defesa da floresta, se dissiparam, enfraquecendo a sua capacidade de propor novas alternativas.

Ao cabo, a produção da farinha tem sido promovida apenas como uma estratégia econômica. Como resultado, perde-se a chance de pensar o fabrico da farinha a partir de referências culturais e alimentares que são essenciais à constituição dessas populações. A conservação da diversidade de mandiocas, os saberes ligados à sua produção, a sociabilidade garantida pelo fabrico da farinha e o próprio modo de vida dessas populações não estão sendo mensurados. São justamente essas referências que poderiam garantir a visibilidade sobre a conservação da agrobiodiversidade nessa região.

\section{Referências bibliográficas}


ALLEGRETTI, Mary. A construção social de políticas públicas. Chico Mendes e o movimento dos seringueiros. Desenvolvimento e Meio Ambiente, n. 18, p. 39-59, 2008.

ALMEIDA, Mauro William Barbosa. Rubber Tappers of the Upper Juruá River: the making of a forest peasantry. Tese (Ph.D.) - University of Cambridge, 1992.

Direitos à floresta e ambientalismo: seringueiros e suas lutas. Revista Brasileira de Ciências Sociais. v. 19, n. 55, p. 33-53, 2004.

ALMEIDA, Mauro; CARNEIRO DA CUNHA, Manuela. (Orgs.) Enciclopédia da floresta - o alto Juruá: práticas e conhecimentos das populações. São Paulo, Companhia das Letras. 2002

CARNEIRO DA CUNHA, Manuela. Introdução. Revista do Patrimônio Histórico e Artístico Nacional - IPHAN. v. 32. Brasília. p. 15-27, 2005.

CARVALHO, Maíra Bueno de. Articulações para o desenvolvimento na floresta: populações locais e políticas públicas em torno da natureza na microrregião de Cruzeiro do Sul, Acre. Tese (Doutorado em Antropologia Social) - Instituto de Filosofia e Ciências Humanas, Universidade Estadual de Campinas, Campinas, SP, 2013.

COSTA, Elisa Mara Lozano. Uma floresta politizada: relações políticas na Reserva Extrativista do Alto Juruá. Tese (Doutorado) - Instituto de Filosofia e Ciências Humanas, Universidade Estadual de Campinas, Campinas, SP, 2010.

GOMES, Carlos Valério et al. Rubber Tapper Identities: political-economic dynamics, livelihood shifts and environmental implications in a changing Amazon. Geoforum, 43, p. 260-271, 2012.

EMPERAIRE, Laure. A agrobiodiversidade, o exemplo das mandiocas na Amazônia. Ciência Hoje, v. 32, n. 187, p. 28-33, 2002.

EMPERAIRE, Laure. A biodiversidade agrícola na Amazônia brasileira. Recurso e Patrimônio. Revista do Patrimônio Histórico e Artístico Nacional - IPHAN. v. 32, p. 15-27, 2005.

EMPERAIRE, Laure et al. Dossiê de registro do sistema agrícola tradicional do Rio Negro. Brasília: ACIRM/IPHA/IRD/Unicamp-CNPq, 2010.

EMPERAIRE, Laure et al. D’Une Production localisée à une indication géographique en Amazonie: les enjeux écologiques de la production de farinha de Cruzeiro do Sul. Cah Agric v. 21, n. 8, p. 25-33, 2012

FEARNSIDE, Philipe Martin. Limiting Factors for Development for Agriculture and Ranching in Brazilian Amazonian. Revista Brasileira de Biologia, v. 57, p.531-549, n. 4, 1997.

HIRSCHMAN, Albert O. O Progresso em Coletividade. Experiências de base na América Latina. Trad. João Francisco Bezerra. Fundação Interamericana, Rosslyn. 1987.

HOMMA, Oyama et al. Determinantes de desmatamento em polos de produção agropecuária no estado do Acre, Amazônia brasileira. Apresentação no 
XLVI Congresso da Sociedade Brasileira de Economia, Administração e Sociologia Rural. Rio Branco - Acre, 20 a 23 de julho de 2008.

IBGE. Instituto Brasileiro de Geografia e Estatística. Produção Agrícola Municipal. Lavoura temporária. Cruzeiro do Sul. Acre. 2013. Disponível em: <http:// www.cidades.ibge.gov.br>. Acesso em: 28/10/2016.

MDA. Ministério do Desenvolvimento Agrário. Sistemas de Informações Territoriais: Plano Territorial do Desenvolvimento Rural Sustentável do Vale do Juruá, Acre, 2011.

MAPA. Ministério da Agricultura. Indicação geográfica. Disponível em < $\underline{\text { http:// }}$ www.agricultura.gov.br/desenvolvimento-sustentavel/indicacao-geografica>. Acesso em: 28/10/2016.

PACTA, Projeto. Agrobiodiversidade e conhecimentos tradicionais associados na Amazônia. Projeto apresentado ao CNPq e o IRD (Institute de Recherche pour le Développement, França). Processo 02000.005654/2005-78. 2004.

PANTOJA, Mariana Ciavatta. Botar roçados. In: ALMEIDA, Mauro; CARNEIRO DA CUNHA, Manuela. (Orgs.). Enciclopédia da floresta - o alto Juruá: práticas e conhecimentos das populações. São Paulo, Companhia das Letras. 2002.

POSTIGO, Augusto de Arruda. A terra vista do alto: usos e percepções acerca do espaço entre os moradores do Rio Bagé, Acre. Tese (Doutorado) - Instituto de Filosofia e Ciências Humanas, Universidade Estadual de Campinas, Campinas, SP, 2010.

REZENDE, Roberto Sanches. Das colocações à vila: processos de urbanização no alto rio Tejo, Acre. Dissertação (Mestrado) - Instituto de Filosofia e Ciências Humanas, Universidade Estadual de Campinas, Campinas, SP, 2010.

SEFAZ. Secretaria de Estado da Fazenda e Gestão da Agência de Cruzeiro do Sul. Exportação de farinha de mandioca do município de 2000 a 2009. Cruzeiro do Sul, Acre, 2010.

SILVEIRA, Jane Simoni. A multidimensionalidade da valorização de produtos locais: implicações para políticas públicas, mercado, território e sustentabilidade na Amazônia. (tese de doutorado) - Centro de Desenvolvimento Sustentável, Universidade de Brasília, 2009.

TASTEVIN, Pe. Constant. Preparação e uso da mandioca na região do Médio-Amazonas e de seus afluentes. Trad. José Ribamar Bessa Freire. In: FAULHABER, Priscila; MONESERRAT, Ruth. Tastevin e a etnografia indígena. Coletânea de textos produzidos em Tefé (AM). Série Monografias. Rio de Janeiro: Museu do Índio/ FUNAI, 2008.

VELTHEM, Lúcia Hussak Van. Farinha, casas de farinha e objetos familiares em Cruzeiro do Sul (Acre). Revista de Antropologia, v. 50 n. 2, p. 605-631, 2007.

VELTHEM, Lúcia Hussak Van; KATZ, Esther. A “farinha especial” fabricação e percepção de um produto da agricultura familiar no vale do rio Juruá. Bol. 
Mus. Para. Emílio Goeldi. Cienc. Hum, v. 7, n. 2, p. 435-456, 2012.

\section{Autora Maira Bueno de Carvalho}

Mestre e Doutora em Antropologia Social pela Universidade Estadual de Campinas. Trabalha com temas de pesquisa ligados à biodiversidade da Amazônia, com especial atenção às políticas de uso e conservação da natureza, desde políticas científicas e tecnológicas (biotecnologia) até agrícolas e ambientais.

Recebido em 25/02/2016 Aceito para publicação em 04/01/2017 